\title{
Medievalista
}

Online

$31 \mid 2022$

Número 31

\section{José Mattoso ou a contemplação como exaltação}

José Mattoso or the contemplation as exaltation

\section{Hermenegildo Fernandes}

\section{(2) OpenEdition}

\section{Journals}

Edição electrónica

URL: https://journals.openedition.org/medievalista/5064

ISSN: 1646-740X

\section{Editora}

Instituto de Estudos Medievais - FCSH-UNL

\section{Refêrencia eletrónica}

Hermenegildo Fernandes, «José Mattoso ou a contemplação como exaltação», Medievalista [Online], 31 | 2022, posto online no dia 01 janeiro 2022, consultado o 02 fevereiro 2022. URL: http:// journals.openedition.org/medievalista/5064

Este documento foi criado de forma automática no dia 2 fevereiro 2022.

\section{cc) (1) 8}

Mediavalista está licenciado com uma Licença Creative Commons - Atribuição-NãoComercial 4.0 Internacional. 


\title{
José Mattoso ou a contemplação como exaltação
}

José Mattoso or the contemplation as exaltation

\author{
Hermenegildo Fernandes
}

\section{NOTA DO EDITOR}

Data recepção do artigo / Received for publication: 6 de Dezembro de 2021

1 Este texto vem do Ensaio "A História Contemplativa", que abre a mais recente colectânea de estudos de José Mattoso. Vem ainda, indirectamente, de um convívio de décadas com a sua obra e também do privilégio especial que decorre de uma experiência insubstituível, a de ter sido seu aluno. No caso, isso significou estar lá no ano anterior ao da publicação da Identificação de um País, nas aulas de História de Portugal, nesse ano lectivo de 1983-1984, organizadas informalmente em semestres, o primeiro a cargo de José Mattoso, o segundo de Iria Gonçalves. Estou bastante seguro do impacto dessa experiência, e de outras simultâneas, na decisão que tomei pouco depois de me tornar medievalista. Antes disso, no entanto, decidira já que queria ser historiador. As glosas que se seguem são mais do ponto de vista da História lato sensu que da medievística. E constituem tanto uma homenagem, muito curta e insuficiente, ao autor do artigo que as origina, como uma tentativa de pensar as operações oficinais identificadas na "História Contemplativa", à luz da crise contemporânea do trabalho do historiador. Porque são glosas, seguirei muito de perto a exposição de José Mattoso e abster-me-ei de notas ou referências. Os números dizem respeito às páginas do texto original.

2 "A História Contemplativa" é, mais do que qualquer outro texto prévio de José Mattoso, o fio de Ariadne através do qual o autor se orientou no labirinto da sua própria obra 
enquanto indivíduo e, por extensão, da História-escrita enquanto actividade de um colectivo. Com isso quero dizer que resulta de uma reflexão a posteriori feita no termo de um longo exercício na condição de historiador activo, em busca de chaves interpretativas que expliquem um posicionamento e uma prática. É, pois, de um mergulho vertical na própria actividade enquanto historiador que advém a definição de uma metodologia e, fundamentalmente, de uma visão do ofício. Por isso e porque o processo é reconstrutivo a partir do seu próprio caso, o autor começa por considerar o seu posicionamento num momento historiográfico que vai da afirmação da Escola dos Annales às "controvérsias do fim do milénio", anunciando desde logo o método da explicitação, assente na utilização de símbolos e metáforas e em particular da metáfora da construção enquanto representação da acção de historiar. Está aqui um primeiro leitmotiv ao qual haveremos de voltar mais tarde, dado tratar-se de um elemento-chave para perceber a relação proposta entre a realidade e representação, ou entre História vivida e História escrita.

Por ora interessaria reter a posição de José Mattoso face aos debates historiográficos do último quartel do século XX e dos inícios do novo milénio, o que tem não só um valor por assim dizer biográfico, mas nos remete ao mesmo tempo para o que ele entende ser o que faz, o que deve fazer, um historiador. Tendo em vista o que se conhece sobre a ligação do Autor à Escola dos Annales, já por ter trabalhado com L. Génicot em Louvaina (ainda que este tenha tido um percurso algo marginal face ao main-stream da historiografia francesa do pós-guerra), já pela constante referência, notória por exemplo na ligação dos "Ricos Homens Infanções e Cavaleiros" aos "Guerreiros e Camponeses", a Georges Duby, várias vezes assumida em entrevistas, não deixa de ser revelador o distanciamento crítico que aqui se evidencia, particularmente em relação à "segunda geração" da Escola: "A este pujante conjunto de tendências e de experiências sem metodologia própria, sem objectivos definidos, e de valor científico muito desigual, com estudos inovadores ao lado de verdadeiras mistificações [...] chamou-se a Nova História" (pp. 13-14). De passagem havia-se sublinhado a mutação resultante da eclosão dos novos objectos (ou talvez antes a sua ascensão a estrelas no campo historiográfico, visto muitos deles não serem verdadeiramente novos), à qual, anote-se à margem, o próprio José Mattoso não deixou de ser episodicamente sensível. Ou ainda o triunfo de uma abordagem estruturalista que se considera aqui menos no seu impacto metodológico do que nas consequências sobre a periodização clássica. A este respeito, aliás, reconhecendo-se o carácter artificioso de qualquer periodização (uma periodização, diria, é um artefacto classificatório que nos serve para inteligir e por essa razão só pode ser construído, como todos os instrumentos ordenadores), sublinha-se o seu valor pedagógico, ficando uma reticência implícita acerca da "nova forma de marcação das épocas" (p. 13) contraditória com aquela que o Iluminismo havia decidido. A esse respeito refere-se o problema da confusa e incipiente recepção das transformações da historiografia no ensino da História, tomando justamente como exemplo a resiliência da periodização em épocas, capaz de sobreviver a todas as mutações no campo (p. 15), resultante diria, quer da sua utilidade pedagógica, quer da própria estruturação académica e funcional do campo historiográfico, quer da resistência de uma espécie de meta discurso capaz de atravessar gerações (daí resultando aliás a sua eficácia social) e de se constituir como uma narrativa socialmente reconhecida por todos, capaz de explicar a totalidade do passado. Anotaria, ainda, como a eficácia dessa narrativa fica demonstrada pela procura da sua extensão a passados não europeus. Penso por exemplo no artifício da identificação de Idades Médias globais. 
Aliás o grande desafio de uma História Global contemporânea estará precisamente em subtrair-se a essa tentação.

4 De tudo isto decorreria, por fim, a ambição da "História Total", cujas derivas nihilistas aqui se debatem, sem, no entanto, podermos deixar de a pensar como uma decorrência da percepção da "conexão entre os vários campos do agir humano" (p. 12) e uma superação aos modelos historicistas responsáveis por uma compartimentação artificiosa de campos. A hesitação, acrescentaria, está entre a necessidade de separar o objecto em tranches manuseáveis para o ensinar e para o estudar, e o imperativo de o considerar no todo, operação necessária para a restituição da inteligibilidade que cada historiador procura.

\section{II}

5 Na observação da Nova História enquanto deriva está, creio, um dos pontos mais interessantes da argumentação inicial do Autor, o da articulação entre essa Escola e a instalação de uma pós-modernidade historiográfica. É na revisão radical da ideia de progresso que orientara as concepções iluministas da História (lembremos sobretudo o Esboço de um Quadro Histórico dos Progressos do Espírito Humano de Condorcet) mas que sobrevive nos caminhos diversos da historiografia romântica e pós-romântica (por exemplo nas metáforas vitalistas spenglerianas, sob a forma de reversão do progresso, ou ainda, claro, nas várias formas do materialismo dialéctico), é nessa revisão radical da ideia de progresso, que José Mattoso encontra as matrizes de uma erosão nihilista que esvazia o sentido e conduz ao cepticismo. A "amálgama a que se chamou pósmodernidade" (p. 14) é assim uma espécie de resultante, nihilista e esvaziadora de sentido da própria Nova História que a teria engendrado tal como o Aufklaerung, diria, gerou o Sturm und drang. A reacção, que imediatamente se segue, surge através do neopositivismo, que aliás nunca havia abandonado completamente as fileiras do medievalismo, porque o estudo das vanguardas historiográficas apresenta muitas semelhanças com o das artísticas, tomando-se amiúde a excepcionalidade das correntes dominantes ou da moda, com a prática comum (quase) universal; surge também através dos estudos de caso (as "monografias de âmbito reduzido") que podem ser uma decorrência do neo-positivismo e uma opção voluntária pela consideração do particular resultante quer de uma opção de fundo pela intangibilidade do real global, quer, mais chãmente, de uma incapacidade de ver mais além da árvore, ou visto de outra forma, uma opção metodológica para chegar por outros caminhos ao mesmo global; revela-se, ainda, na utilização crescente das "técnicas laboratoriais das ciências exactas" (p. 14), isto é, numa crescente procura de legitimidade social e metodológica fora do campo historiográfico, procura essa tornada obsessiva nos últimos anos.

III

Retomarei alguns desses fins condutores nas glosas finais. Por ora interessar-me-ia reter um aspecto particular da argumentação, o da crítica aos estudos de caso: "As sínteses foram desvalorizadas ou até proscritas. Multiplicaram-se as monografias de validade epistemológica limitada. Reduziram-se os objectos de estudo. Praticou-se a micro-história" (p. 14). A crítica ao programa monográfico é, parece-me, muito certeira. Não porque as monografias não tenham um papel essencial na produção 
historiográfica, mas porque esse papel deverá estar condicionado pela capacidade de a observação local responder a questões globais. Julgo que aqui José Mattoso visava, no entanto, mais longe e mais alto do que a redução, de resto bastante conservadora e tradicionalista, do objecto à esfera local. Em causa está antes uma renúncia à síntese e à explicação, substituída nalgumas abordagens pós-modernas por uma observação analítica e descritiva de situações, por isso sempre ao nível micro, que se entende falarem por si, da mesma forma que a história crítica de matriz oitocentista entendia poderem falar sozinhas as compilações documentais a que dedicaram (e bem) um tão grande afã publicista. Vista desta perspectiva de redução não só dos objectos de estudo, mas da própria intenção interpretativa, entende-se a crítica de uma racionalidade micro-histórica empreendida aqui pelo Autor.

Parece-me possível, no entanto, resgatar a operação, talvez aquela saída da oficina da pós-modernidade com mais potencial de operacionalidade metodológica e conceptual. Primeiro, porque a micro-história deve partir de problemas gerais para no particular responder a eles e através dessa operação voltar ao global. Nesse sentido não me parece possível qualquer interrogação de situações concretas fora de um quadro interpretativo e conceptual global e das perguntas precisas que ele suscita. Fora disso, estamos perante uma narrativa ou uma sequência de narrativas sem intenção explicativa e por isso, do ponto de vista deste outro autor, fora da esfera histórica propriamente dita. Essa premissa não pode ser confundida, creio, com a rejeição da situação e do fragmento enquanto local de exercício da operação histórica, por razões que se podem esclarecer numa segunda linha de observações. De facto, e em segundo lugar, se a micro-história pode resultar de uma recusa das sínteses, também pode bem servir de lugar de observação, isto é, de desvelação, no sentido que mais adiante José Mattoso dá ao termo. Quero com isto dizer que a observação de situações precisas constitui uma forma de restituir a totalidade tão ambicionada pelos Annales e que constitui o principal desiderato das operações propostas pelo Autor na segunda parte do artigo, porque permite ver e compreender, as duas operações aparentemente tão simples que estão por detrás da acção de historiar. Pelo que, ao invés da renúncia à explicação que tão apressadamente alguns seguidores fizeram derivar da micro-História, o método conduz à explicação e à reconstrução de uma visão integral, isto é, da síntese.

8 Essa mesma aproximação poderá resolver os riscos de fragmentação disciplinar a que o Autor alude (p. 15). Esta, é verdade, mergulha as suas raízes na própria tradição da História académica e antecede em muito por isso a pós-modernidade, que dificilmente será apontada como causadora de uma visão da realidade às fatias. Creio, nesse sentido, que não se pode confundir uma segmentação do campo historiográfico por áreas disciplinares, que embora prática sempre impediu de ver o todo, com a renúncia à explicação ou, pior, a reconstrução da explicação a partir de áreas precisas parcelares, falsamente autonomizáveis (penso por exemplo em tentações a partir do domínio da História Económica). No caso preciso da micro-História, pelo contrário, pode cumprirse o programa proposto por José Mattoso quando fala da "perspectiva totalizante da visão contemplativa" enquanto forma de "ver a realidade de um ponto fixo a partir do qual pudesse abranger todo o passado" (p. 16). Dito de outra forma, do meu ponto de vista, o estudo de caso é esse ponto fixo cuja reiterada observação constitui o lugar de manifestação da visão contemplativa que leva à compreensão e à explicação, o particular sendo o ponto de "desvelação" do total. Assim, da mesma forma que, segundo o Autor a pós-modernidade emerge da Nova História, também aquela contém 
em si, talvez de forma inesperada para os seus praticantes, contradições capazes de suscitar uma outra construção.

\section{IV}

9 bem demonstrado pela rejeição de um mau exemplo desta última, as observações
proféticas de F. Fukuyama sobre o fim da História, fica a dever-se aos princípios (p. 17) que o Autor reconhece como centrais à prática do historiador.

É, no entanto, revelador que se inicie esta parte da exposição por um reconhecimento da veracidade das críticas pós-modernas à projecção de conceitos contemporâneos sobre o passado. Um dos pontos fulcrais será a necessidade de estar atento às variações semânticas e a consequente extensão do significado de crítica histórica. Parece-me este um dos pontos mais importantes a reter no conjunto de observações de José Mattoso sobre as transformações da historiografia nas últimas décadas: compreender implica não retroprojetar mecanicamente conceitos contemporâneos do observador sobre os do tempo do objecto (o advérbio é aqui essencial, porque qualquer esforço de inteligibilidade pressupõe a aplicação de conceitos provenientes do observador); isso por sua vez implica complexas operações de restituição de sentido, isto é, de reconstrução das variações semânticas que um mesmo nome sofre no decurso cronológico da sua utilização. Foi esse o caminho escolhido pela História Conceptual, numa abordagem que me parece ainda escassamente recebida pelo medievalismo. Creio, porém, que a recusa da aplicação acrítica de conceitos do lado do observador, visível já desde o debate dos anos sessenta em torno da dicotomia ordens/classes, (e lançada em Portugal com tantos frutos por António Manuel Hespanha através de uma operação que conduz da desconstrução marxista dos conceitos enquanto ideologia a uma pós-modernidade em que se pode correr o risco de só haver representação), não pode dar lugar à tentação de buscar uma reconstrução total operada do lado do objecto. Isto não só porque se trata de uma operação irrealizável, à imagem do mapa na escala 1/1 de que fala Jorge Luís Borges, mas também porque a operação de restituição da semântica conceptual do lado do objecto revela a imensa complexidade de visões que resultam da reflexão de uma sociedade sobre si própria e o carácter ideológico de muitas delas, como mostrou Georges Duby no livro seminal sobre o impacto da ideia das ordens no imaginário do feudalismo. É aliás evidente no texto de José Mattoso a relevância do exemplo das categorizações sociais (às quais dedicou uma parte importante da sua obra, ao estudar a génese da nobreza medieval portuguesa), para pensar as relações entre o objecto e as suas representações, elas próprias, acrescentaríamos, objecto (p. 19).

\section{V}

A História será sempre por isso representação. E dessa consciência resulta a distinção entre História-escrita e História-vivida que vai buscar a Paul Ricoeur. Assim, tal como recorremos a metáforas para representar o social, José Mattoso propõe a noção de maquete como forma de representar a relação entre realidade e réplica (p. 20). Porque esta metáfora é essencial e muito reveladora do percurso do autor, a sua aptidão pelo desenho e as artes plásticas estando-lhe na origem, e porque ela representa ao mesmo 
tempo o reconhecimento da impossibilidade do mapa $1 / 1$ de que falava há pouco, valerá a pena identificar as suas componentes e modo de construção.

O ponto de partida está na observação da "História enquanto objecto plástico", feito de materiais concretos que formam a maquete, tempo e espaço, harmonizados funcionalmente. Essas são as coordenadas de leitura que permitem ao historiador/ observador movimentar-se dentro da construção, mas esta faz-se a partir de indícios: marcas físicas, sempre discursos unilaterais porque não os podemos interrogar directamente (p. 21). A perspectiva aqui é claramente a de um medievalista, anotaríamos, e poderia ser contestada pela crescente falange de seguidores da História do tempo presente. Poderemos, porém, perguntar se a condição do historiador, assim como a sua prática, não implica uma certa distância em relação ao objecto, também cronológica, coisa que o separa do sociólogo ou do antropólogo, seus primos mais jovens.

Esses indícios são interrogados através de algumas operações (como há muito tempo ensinou José Mattoso a um grupo de jovens aprendizes de historiador) bastante simples na sua essência: seriação, medida. A mensurabilidade é aliás o essencial, já na construção de tabelas cronológicas, já na produção de dados quantitativos (p. 22). A distinção, também feita por Jacques Le Goff entre documentos e monumentos (p. 23) é aqui essencial, porque separa as fontes que fornecem os indícios da construção resultante da submissão delas às operações de exegese. E é nesse sentido que os factos se distinguem dos indícios, resultando aqueles depois da submissão destes a um conjunto de procedimentos heurísticos, semióticos e semânticos que implicam a verificação das lacunas, a formulação de deduções e de hipóteses e, finalmente, a demonstração (p. 23). Estas fases conduzem à construção material da maquete e é essa função material que acaba por lhe dar um destino (p. 24). Toda a maquete concorre assim, desde os alicerces, para uma finalidade, a interpretação, que implica a hipótese, a síntese formulada através de uma narrativa. A simplicidade e ao mesmo tempo o rigor implícito nesta racionalização da operação em História parecem-me características de sempre da historiografia de José Mattoso, ainda mesmo antes de serem formuladas por escrito. Não podemos ter dúvidas que estiveram sempre lá antes deste momento de reflexão a posteriori.

\section{VI}

O aparente conforto do sistema é, no entanto, abalado por uma demonstração prática, à escala do social, do princípio da incerteza de Heisenberg: a maquete, que está ao mesmo tempo próxima e distante da História Crítica com raízes em Seiscentos, é flexível e move-se sem deixar de ser maquete, como a máquina de habitar de Le Corbusier era ainda uma casa ao mesmo tempo que estilhaçava o paradigma clássico das regras de habitar oitocentistas. Aliás, o que melhor caracteriza a maquete é a sua mobilidade em "direcção a destinos imprevisíveis" (p. 25), isto é, a impossibilidade de determinações lineares e, no limite, da previsão. A crítica a Fukuyama e às filosofias da História, mesmo que mais plausíveis porque não cortando radicalmente com a inevitabilidade da mudança e o carácter incontrolável dela, vem daqui, desta assunção radical da imprevisibilidade como parte da História que a deve separar em método e expectativas, diria, das outras ciências que buscam o previsível e por isso a lei (pp. 25 e 26). 

rejeição às armadilhas da submissão da História às ideologias que congelam a maquete, apertando-a em sistemas interpretativos rígidos e pré-definidos, perigos que a deriva da pós-modernidade acentua, através do nihilismo do "tudo é ideologia"; e também no que implica de reconhecimento de que enquanto máquina de representação, a "História escrita" tem entre mãos um objecto volátil que é melhor descrito como uma maquete em movimento aberto. E é justamente esse carácter aberto que nos deve prevenir contra as armadilhas do "fascínio da totalidade" (p. 26), tema que já tinha aparecido a propósito da História total dos Annales, e que neste momento pode servir de aproximação aos limites de uma história global, entendida como totalidade radical em espaços/tempos que escapavam ao conceito da universalidade oitocentista.

E justamente no domínio dos espaços/tempo reflecte-se também o tópico da imprevisibilidade, do não automatismo e da complexidade. Em primeiro lugar, de novo a propósito da periodização tradicional e das suas vantagens pedagógicas, resultantes da necessidade de "aquisição da noção de tempo real" (p. 27), ao mesmo tempo que se reconhece esta enquanto artefacto. De igual forma no que respeita ao espaço, sublinhando-se que "a distinção geográfica enriquece a noção de época" (p. 27) e, acrescentaríamos, não só a enriquece como a desdobra, permitindo substituir a uma linearidade focada numa área regional (por exemplo o mundo romano ou a "Europa medieval"), múltiplos espácio-temporais potencialmente conectados, mas não necessariamente síncronos nem passíveis de serem submetidos a um único sistema explicativo. Ao artefacto contrapõe-se assim a fluidez e a variedade histórica que José Mattoso aproxima aos caprichos da orografia, picos mais altos, vales e rios (p. 28) servindo de metáfora (mais uma) à diversidade e imprevisibilidade do objecto que a maquete deve acomodar.

\section{VII}

Chegamos aqui ao momento fulcral do sistema, isto é, ao que fazer com a maquete, ou, dito de outra forma, às condições e possibilidades da sua operação. $O$ Autor distingue a esse propósito duas aproximações diferentes, resumíveis na dicotomia technê versus poiesis (arte) (pp. 28-29). Poderíamos dizer que a oposição é matricial à formação do próprio conceito de História enquanto investigação e, por essa razão, narrativa que se distingue da épica pela procura da verificação e a referência das fontes. Uma vez codificadas essas regras, o que acontece em temporalidades diversas, na Grécia Clássica, no Islão Medieval, na Europa Humanista ou Iluminista, assume-se que a poiesis deve ser apoiada numa technê, mesmo se no mundo clássico como na latinidade medieval, a História é ensinada a propósito das artes do discurso, a Gramática e a Retórica. Os riscos contemporâneos, mutuamente contraditórios, de separação entre technê e poiesis, decorrem, por um lado de uma pós-modernidade radical disposta a transformar tudo em discursos, por isso mesmo sem relação necessária com um objecto real e, por outro, da submissão à operação quantitativa/métrica proveniente das ciências "exactas". No primeiro caso tudo fica reduzido a uma poiesis esterilizante. No segundo a uma technê autoexplicativa que dispensa, no fundo, todo o imenso trabalho preliminar de construção da maquete e, mais ainda, a interpretação que nela se apoia.

Nesse sentido creio que o domínio sobre o conjunto de técnicas a que os antigos chamavam "Artes" (technê) enquanto "invenzione" (poiesis) é o que no fim de contas 
distingue o bom historiador do mau. As operações preliminares enquanto "Arte" podem e devem aprender-se, mas os mecanismos dos quais depende a "invenzione" (correlações de variáveis, associação de factos, comparações e capacidade retórica, do ponto de vista narrativo ou enunciativo) resultam amiúde da livre associação que se manifesta no decurso da formulação discursiva, seja ela oral ou escrita. Pode assim pensar-se na analogia entre o exercício histórico diante de um público (oral) e a necessária fluidez para o manter vivo na versão escrita. Em ambos os casos, trata-se de um processo imersivo e de alheamento de todo o real fora daquele que instantaneamente se historia. Só a imersão garante o necessário estado de alteração de consciência necessário para mobilizar grandes massas de informação para a construção de uma explicação que as organize e lhes possa garantir um sentido. Tudo isto só se aprende, ou não, fazendo. E fazendo durante muito tempo.

O ponto que José Mattoso aqui faz não é centralmente sobre a technê, ainda que esta lhe mereça algumas considerações relevantes, motivadas pela retoma da metáfora do detective que acumula indícios e provas através de técnicas específicas (p. 29). Muitas delas já são utilizadas pela História Crítica, com fundamentos que vão de Valla a Mabillon. Juntam-se aqui alguns sublinhados. Refiro-me às dificuldades suplementares introduzidas pela evolução da história do pensamento e dos sistemas de representação (p. 30), e às armadilhas que colocam a quem procura centrar-se no objecto; aos perigos de um abandono radical da maquete pré-existente (p. 31) que derivam dessa evolução e da reinterpretação permanente (diria eu) das relações entre technê e poiesis. Daí o vincar da importância das cadeias de transmissão (no sentido em que as toma o Islão medieval, de Isnad) no lugar da rápida substituição de sistemas, com a finalidade de vincar o triunfo efémero de cada geração historiográfica sobre as anteriores. Ainda a um aspecto que o Autor reputa central na technê: "a escrita clara e simples" (p. 32), que é sem dúvida marca de água na sua historiografia. Mais uma indicação de que no fundo da technê está o estilo. Entendido não enquanto forma, mas como processo de inteligibilidade do objecto. Finalmente, o pressuposto básico de que a História escrita é narrativa e narrativa de mutação, do que muda, ou, como diria outro grande historiador, Jorge Borges de Macedo, do que vai mudando. Isso implica um reconhecimento de que os instrumentos conceptuais, como as estruturas, "não são seres reais mas criações" dos historiadores para introduzir ordem e sentido (p. 34). E, portanto, produtos da technê. O mesmo se poderia dizer dos instrumentos de medida criados para poder reduzir ao número o real (como o PIB, por exemplo). Porém, das leis históricas do historicismo às regularidades (as "secretas linhas de força" do estruturalismo), encontramo-nos também no limiar da poiesis, porque ao perceber a História viva como "organismo vital" encetamos uma busca do sentido das coisas (p. 33) que só ela pode resolver.

\section{VIII}

20 Chegamos aqui, por fim, ao ponto nevrálgico da concepção da actividade do historiador que dá título ao artigo e conexão aos diferentes pontos de observação que marcam a obra de José Mattoso. Creio, no entanto, que o argumento é tão largo que amplamente a transcende. Se a História é consciência de si colectiva (selbstbewusstsein), essa tomada de consciência provoca uma busca irreprimível de sentido. A atitude de quem busca esse sentido é a contemplação enquanto percepção do "sentido último do Ser" (p. 34). o 
argumento bebe aqui reconhecidamente nas concepções de História enquanto poiêsis de Paul Ricoeur e Martin Heidegger (p. 35), mas convoca ainda Sophia de Mello Breyner e Alberto Caeiro, de forma que é tudo menos ornamental. No fundo não explícito da imagem vislumbram-se as duas décadas beneditinas do Autor, ou talvez mais precisamente a busca da contemplação que o levou lá e que se terá mantido sempre nele, mesmo no século. A operação, porém, está fundada numa sólida argumentação epistemológica.

Parte do reconhecimento de que a memória está sempre limitada pela fragmentaridade, só a contemplação podendo restituir a unidade ("unicidade") que é o destino último e o lugar da compreensão e da inteligibilidade (p. 35). Anotaria, pelo meu lado, que talvez se possa encontrar o sentido precisamente nessa fragmentaridade, restos de restos de restos, que o tempo, como os ladrões de Schiller (Die Raueber) vistos pelo filme de 0 . Iosseliani (Os Favoritos da Lua), nos deixa apreender enquanto reminiscência, e no quadro que conseguimos reconstituir com esses fragmentos. Assim, em vez da busca da unicidade, teríamos a da legibilidade e a intuição do real que a contemplação consente.

Dois conceitos chave são evocados por José Mattoso a propósito da contemplação: desvelação e exaltação. Juntos constituem a chave de acesso à forma como o autor entende o exercício contemplativo. 0 primeiro toma-o a Heidegger, sendo a desvelação a fruição do belo (p. 36). o sentido não é pois estritamente histórico, mas poderá ser capitalizado se pensarmos a desvelação enquanto acesso à totalidade que é a contemplação da beleza última. Irresistível lembrar a propósito o poema de Álvaro de Campos, "O Teorema de Pitágoras é tão belo como a Vénus de Milo". Os cépticos objectarão que estamos no domínio da Metafísica, sendo a História do domínio da Física ou, dito de outra forma, que o Ser é um universal e a História se ocupa dos particulares, ao contrário da Teologia e da Filosofia. Creio, no entanto, que as observações do Autor merecem ser consideradas no que têm de acesso a uma operação fulcral no exercício do historiador, ou aliás, no de qualquer outro cientista. De forma prosaica poderíamos chamar a esse momento "intuição", conceito que, contudo, está longe de esgotar todas as possibilidades do momento (ou da sucessão de pequenos momentos) de acesso à evidência. A história da ciência está de resto cheia de relatos mais ou menos anedócticos desses momentos, podendo de entre eles a maçã de Newton servir por todos. Mas o processo nada tem de irrelevante. É o momento em que todas as variáveis, sequências acumuladas, referências múltiplas, uma complexa estratigrafia em que todo o conhecimento sedimentado é mobilizado para esclarecer um problema determinado. É o momento em que se sabe, isto é, para seguir a formulação do Autor, a totalidade nos atinge enquanto clarão e evidência. É Caeiro e a espantosa realidade das coisas, ou "a percepção do fulgor poético captado graças à inserção do instante na totalidade" (pp. 37- 38).

Neste sentido Sophia (de Mello Breyner) prefigura no texto de José Mattoso, a busca de SOPHIA: a descoberta da realidade enquanto exaltação. Desvelar surge assim enquanto comunicação da exaltação, do momento em que o belo se revela na totalidade (pp. 38-39). Trabalhando sem a rede do original da maquete (p. 40) o historiador produz um conhecimento, a História escrita, "fruto de uma dedicação sustentada pela poiêsis, [que] pode desembocar na contemplação da realidade das coisas." A boa História revela-se assim na "capacidade para evocar" a espantosa realidade das coisas: "um olhar atento, global, pacífico, não interventivo". Essa é a matriz da História escrita enquanto contemplação (pp. 41-42). 
Nesta última frase programática, que é também o resumo de um legado, espreita no subtexto a recusa da aceitação voluntária do filtro das ideologias. Nela está talvez uma pista de resposta aos desafios maiores que se colocam à História hoje. Anoto-os, para terminar, de forma telegráfica (a eles voltarei noutro lugar). Como muitas das coisas que se dizem nestas glosas são da minha estrita responsabilidade e não do Autor que aqui se comenta.

Em primeiro lugar colocaria precisamente a renúncia nihilista a um olhar distanciado das ideologias (tudo é ideologia ergo a história é ideologia). A recusa desta posição perpassa quase subliminarmente neste texto de José Mattoso sobre a História Contemplativa. É hoje mais actual do que nunca, a cartilha das ideologias nacionalistas e das suas oposições marxistas tendo sido substituída pela dos Estudos pós-coloniais, pela agenda descolonizadora e pela valorização acharné dos estudos sobre grupos minoritários ou pseudo-minoritários. Nem as velhas agendas nem as novas contribuem para ver melhor. Nenhuma desvelação aqui, apenas obscurecimento.

Em segundo lugar, anota-se a emergência de uma armadilha recente, a da intermutabilidade entre a technê própria da História e a das ciências exactas, que submete aquela a esta, diluindo o campo e, no limite, o próprio objecto de estudo e o sistema de interpretação. A opção é aqui mais uma vez eminentemente política e implica deixar de pensar historicamente para pensar tecnicamente. $O$ triunfo das Ciências do Património é muitas vezes o lugar onde esta obliteração deliberada, alimentada pelas regras que valorizam um tipo determinado de produção e difusão do conhecimento, se concretiza.

Em terceiro lugar, a diluição dos limites disciplinares, que não pode ser confundida com a interdisciplinaridade e que pelo contrário a impede, por não haver interdisciplinaridade se não houver disciplinas. Ela decorre parcialmente da operação anterior (a segunda), expondo a História à ofensiva das ciências exactas (sobretudo experimentais) e não aos seus benefícios, o inverso não se verificando. É, pois, neste caso, uma operação unilateral. Mas decorre também de um comércio cada vez mais difuso e pastoso com outras ciências sociais, que encontram na versão contemporânea da pós-modernidade um campo ilimitado de expressão. Essa ausência de limites tende a canibalizar o campo histórico e, o que é mais grave, a esvaziar o questionário da variável espaço/tempo, ou dizendo ainda de outra maneira, da technê e da poiesis próprias da História.

Finalmente, em quarto lugar, está em curso um estreitamento míope da cronologia que compromete a compreensão (a exaltação), pela redução da espessura cronológica e a preferência pelo contemporâneo, lido aqui não como uma referência às tradicionais divisões cronológicas que regravam o trabalho do historiador, mas enquanto vocação para o imediato ou para a História do tempo presente, o que mais acentua a diluição de limites do campo com o das outras ciências sociais. A redução da espessura cronológica é em si já bastante ameaçadora, não porque se estudem mais umas épocas do que as outras, mas porque ver apenas na curta duração, um dos registos possíveis para um historiador, é amputar o campo de visão e comprometer por isso a exaltação que advém da consideração dos múltiplos temporais em que as sociedades se movimentam. 
que devem ser tanto mais considerados quanto, neste momento, como o João Carlos no início do Cavaleiro Andante de Almeida Faria, a "História escrita" não sabe sequer se tem futuro.

\section{BIBLIOGRAFIA}

DUBY, Georges - Guerreiros e Camponeses - Os primórdios do crescimento económico europeu, séc. VII-XII. Lisboa: Estampa, 1980.

DUBY, Georges - As Três Ordens ou o Imaginário do Feudalismo. Lisboa: Estampa, 1982.

FUKUYAMA, Francis - O Fim da História e o Último Homem. Lisboa: Gradiva, 1992.

LE GOFF, Jacques - “Documento / Monumento”. In Enciclopédia Eunaudi. Vol. I. MemóriaHistória. Lisboa: INCM, 1984, pp. 95-106.

MATTOSO, José - A Nobreza Medieval Portuguesa - A família e o poder. Lisboa: Estampa, 1981.

MATTOSO, José - Ricos-Homens, Infanções e Cavaleiros - A nobreza medieval portuguesa nos séculos XI e XII. Lisboa: Guimarães Editora, 1982.

MATTOSO, José - Identificação de um país - Ensaio sobre as origens de Portugal: 1096-1325, 2 vols. Lisboa: Estampa, 1985-1986.

MATTOSO, José - “A História Contemplativa - Ensaio”. In MATTOSO, José - A História Contemplativa - Ensaio. Lisboa: Círculo de Leitores - Temas e Debates, 2020, pp. 9-42.

RICOEUR, Paul - Temps et Récit. 3 vols. Paris: Seuil, 1983-1985.

\section{AUTOR}

\section{HERMENEGILDO FERNANDES}

Universidade de Lisboa, Faculdade de Letras, Centro de História, 1600-214 Lisboa, Portugal. hermenegildo.f@letras.ulisboa.pt. https://orcid.org/0000-0003-0760-2429 